\title{
Psychological guidelines in the management of paediatric organ transplantation
}

\author{
Roger Bradford, Laura Tomlinson
}

Organ transplantation is increasingly being seen as the preferred treatment for several life threatening disorders of childhood. Though the early history of liver transplantation in the United Kingdom was not promising (only seven transplants were carried out on children under the age of 16 by 1983 and none survived longer than seven weeks), current one year survival rates exceed $60 \%{ }^{1}$ Heart and heart-lung transplantation are now also available for some children, and increasing rates of success are being reported. ${ }^{2}$ The advances that can be achieved are best seen in renal transplantation, in which the actuarial survival rate for children who received transplants between November $1968-$ December 1987 is $79 \%$ after 14 years, and for those who received transplants since October 1983 , is $94 \%$ after four years. ${ }^{3}$

In the light of these results, teams are becoming increasingly aware of the need to implement practices that will enhance children's adjustment both in the short term and the long term. The purpose of this paper is to review the psychological issues encountered by children and families facing transplantation and highlight guidelines for clinical practice.

\section{Discussing transplantation}

In most cases it is possible to discuss the likely need for transplantation with the family. With the increasing technical success of renal transplantation it is becoming possible to take psychosocial factors into consideration when planning the optimal time for the operation, to maximise the quality of life for both child and family. The balancing of medical and psychosocial factors to make the operation as successful as possible is likely to become an important goal for all teams.

Gold $e t$ al identified two way in which parents may react to the information about transplantation that can present problems for teams. ${ }^{4}$ The first entails being highly assertive, and is often reflected in having difficulties in relinquishing control of their child's management, seeking detailed information about the procedures to be undergone, and requesting second opinions. Medical and nursing teams alike find this both overdemanding and undermining, and it gives the families the appearance of being emotionally detached in their relentless pursuit of information. It is often at this time that mental health workers are asked to become concerned because of worries that the family may be denying the inevitability of their child's condition.

Despite the tensions that this style of coping sometimes produces, it is often one of the most successful ways of dealing with what might other- wise be overwhelming. ${ }^{5}$ The pitfall for the medical team occurs when tensions become heightened to the extent that communication breaks down between them and the families. It is important that such families are recognised early on so that strenuous efforts can be made to form a working alliance by regular consultations, thereby promoting trust and confidence, and by keeping the parents as fully informed and involved as possible. In our experience it is also essential that the team nominates a key person, usually a senior member of staff, through whom communication with the family is filtered. This reduces the likelihood of friction occurring between members of the team and the family.

An alternative way of dealing with the news about transplantation is for families to become 'underorganised'. Because of their apparent compliance, these parents seem to present no overt concerns for medical teams. The pitfall is the assumption that the family have a clear understanding of the procedure and its implications. In general, patients' knowledge of body systems is poor. Fewer than half of adult patients know the location of important organs, ${ }^{6}$ and many have misconceptions about their functions and how treatment relates to them. ${ }^{7}$ In addition, their understanding of medical terms in common use is often confused, ${ }^{6}$ and families commonly have questions that they feel too inhibited to ask. Bradford found that a third of patients on a liver unit failed to ask the questions that they wanted. ${ }^{8} \mathrm{~A}$ common misconception for families is the anticipation that after transplantation their child will be 'as new', and as a result they minimise the continuing need for drugs and visits to hospital. It is only in discussing transplantation with the family, and through eliciting information rather than just imparting it, that the lack of knowledge and the misconceptions that they harbour become clear.

An issue that often confronts transplant teams is how much and in what way children should be informed of their illness and forthcoming operation. Evidence from paediatric oncologists suggests that the knowledge children have of their illness and the way in which it is acquired is associated with psychological adjustment in later life. ${ }^{9}$ Children who were informed of their diagnosis directly and at an early stage - that is, within a year of diagnosis or by the age of 6 years-were better adjusted than those who were not told or who acquired the information through indirect channels such as by overhearing. Similarly, parents often want to know what they should tell the other children in the family. By studying the siblings of children who had died it was found that keeping a child informed of a brother's or sister's diagnosis 
and prognosis was an important protective factor in later adjustment. ${ }^{10}$ Transplantation has a profound effect on every member of the family and efforts should be made to help parents recognise the need for open communication, which should clearly include discussion with their other children.

The way in which a child should be told about transplantation needs to take into account both the emotional and the cognitive development, because a child's knowledge about the body, its functioning, and the causes and prevention of illness and treatment, is related to the developmental stage. Preschool children tend to think that illness has a magical explanation or alternatively as being a result of their behaviour, usually a wrongdoing. ${ }^{1}$ Consequently, treatment is often seen as a punishment. Primary school children think that illness is caused by germs or contamination. ${ }^{10}$ Thus these children are likely to understand procedures such as barrier nursing but may fail to understand the need for immunosuppressive treatment and frequent blood tests. It is not until the teenage years that a clear concept of the body as a functioning system emerges. ${ }^{12}$

Surprisingly, research on doctor-patient interaction suggests that paediatricians often fail to speak directly to their patients. ${ }^{13}$ It would seem therefore that doctors need to communicate more, particularly to reassure the preschool age group about the causes of their admissions to hospital and illnesses, to discuss anxieties about treatment with primary school age children, and to hold open and frank consultations with older children.

The prospect of a transplant obviously provokes anxiety. There is therefore a need to help children and their families discuss and cope with the forthcoming admission and procedure, and in particular to identify those who are most likely to adjust badly. ${ }^{14}$ Factors that increase vulnerability include maternal mental health, poor communication and lack of cohesion within the family, lack of social supports, and a previous psychiatric history in the patient. ${ }^{15}$

Psychological interventions help to reduce distress for both child and parents, reduce the need for drugs, speed up the discharge, and improve the adjustment back to home life. ${ }^{16} \mathrm{~A}$ number of techniques can be used to facilitate coping, including visits before admission, ${ }^{17}$ videos of actors playing appropriate scenes, ${ }^{18}$ organised play, ${ }^{19}$ and by providing information and emotional support for parents. ${ }^{15}$ Careful preparation before admission is clearly vital for transplant patients, many of whom will enter hospital at short notice. It is important that these families are made familiar early on with the ward and with the staff who will support them throughout their stay, but also that they should be prepared for the procedures, sights, and sounds they will experience. Scrap books and photograph albums of other children during various stages of their treatment can be invaluable aids that are relatively easy and inexpensive to provide. It may also be helpful to offer written advice about what practical steps need to be taken to prepare for admission.

During this period the team will want to foster a positive attitude in the family about the forthcoming operation. The reality that some procedures are unsuccessful, however, also needs to be acknowledged. The team needs to be aware of and plan for the support the family will require if the operation fails and the child dies, as well as the profound effect that such an event has on staff and other families on the unit. The bereaved family will often look for support during this period to those members of staff whom they already know. It is important to recognise that a main source of stress among staff is the sense of impotence that they feel when they are unable to relieve the distress of parents who have lost a child. Woolley et al identified particular issues of staff finding parental anger, as part of the grief response, being difficult to cope with. ${ }^{20}$ It is advisable therefore that all members of the team, including the most junior, should be familiar with the processes of grief, and know what to do when faced by grieving parents and siblings. ${ }^{21}$ In our experience it is important that the members of the unit have the opportunity to explore their own feelings about the loss of a child. Where this is seen as too threatening or inappropriate it is possible to approach the topic by offering a structured session on the psychology of death and grieving. This usually opens out into a discussion of events on the unit and allows staff to deal with their own feelings at their own pace.

\section{After transplantation}

\section{IMMEDIATELY AFTER THE OPERATION}

After transplantation children will spend variable amounts of time in the intensive care unit. Though there is little evidence about the emotional effects of being in an intensive care unit on children, there have been a number of studies of parents' reactions. Specific areas of parental concern include the sights and sounds associated with the physical environment such as monitor alarms, equipment, and other ill children. They are worried about the child's appearance, mood changes in older children, procedures carried out on their child, such as the taking of blood, the insertion of catheters and cannulas, and physiotherapy treatment. Parents are concerned about staff behaviour and communications including the use of jargon, levity, and apparent remoteness; how they should behave in relation to their child and the lack of a clear role; and the child's behaviour, when this included confusional states, demanding, or inactivity. ${ }^{22}$ These authors advocate the need for clear communication about what to expect and what the parents' role is.

A common complication immediately after the operation is infection and the need for barrier nursing. The isolation associated with this form of treatment can lead to the child reacting with anger towards staff and parents, poor compliance, and tearfulness. Structuring the child's day so that boredom and loneliness are minimised, as well as ensuring that the child can communicate, is an essential part of nursing care. This can include incorporating free play periods with nursing staff who may otherwise have limited contact other than during aversive procedures, the creative use of video and television give the child access to what is happening outside the room, and communication with peers by audio tapes.

A number of psychological techniques have been developed to help children cope with specific medical procedures. These include giving the child clear signals and advance warning that a procedure will take place by-for exampleexplaining that blood will only be taken when the nurse wears a red badge, helping the child to take part in the actual intervention, 23 teaching relaxation by breathing exercises and imagining pleasant scenes, ${ }^{24}$ acting out scenes of effective coping and 
talking positively, ${ }^{25}$ and using the child's ability to imagine a favourite character, such as Super Ted, dealing appropriately with such circumstances. In addition, staff can increase the child's compliance by rewarding good behaviour during procedures with star charts, bravery certificates, and badges. ${ }^{26}$

In the weeks after transplantation it is not uncommon for children to experience changes of mood including unhappiness, crying, and mild depression, which in most cases reach a peak about a month after the operation. ${ }^{27}$ Parents should be warned about this, both to ameliorate the child's distress and decrease their own anxiety. It may also help parents to achieve an appropriate balance in their approach to their child. A particular concern at this stage of the child's recovery is infection. For patients who have received liver transplants this is a common complication that serves to highlight for both child and parent their continuing vulnerability. It can also arise in patients who have received kidney transplants and who, despite previous information, regard the failure of the graft to provide adequate function immediately as an ominous sign. The emotional state of both parent and child is usually closely related to the course of the medical condition, with disturbance being associated with periods of infection, rejection, and poor functioning of the graft. This continuous raising of hopes matched by periods of disillusionment can result in conflicts developing and becoming overt, expression of anger, and even distancing from the patient. The process may be mirrored within the team treating the child, with staff adopting polarised positions in relation to the child's continuing treatment. Ideally these conflicts need to be acknowledged and steps taken to reach a consensus. The reality is often more complex because of the differing burdens of professional responsibility.

AT THE TIME OF DISCHARGE

As the child's medical condition becomes more stable, the team becomes increasingly aware of the need to help the child back into a more normal pattern of life. Of particular concern to both parents and children are the problems of losing contact with peer groups, falling behind with schoolwork, and the types of restrictions that may be imposed on the child's physical recreation. Brookes reported that the child's return to school after the operation is often most stressful, ${ }^{28}$ and clearly this needs to be planned in advance. In addition to children and parents this process should include teaching the staff both from the hospital and the school, as well as doctors, to provide accurate information on the child's needs and abilities and to dispel myths and reduce anxieties about the child's vulnerability. Overprotection by others is a common problem for children with chronic disorders, and this is also true for children with transplanted organs. ${ }^{27} 29$

It is therefore important that medical staff actively inquire about the child's acquisition of an appropriate degree of independence when seen for follow up. ${ }^{8}$ Where it is possible for teams to work in a multidisciplinary fashion much of this kind of follow up is appropriately carried out by other, non-medical, members of the team such as teachers, who may be able to approach the child's school to get a wider picture. If the team do have concerns about the adequacy of the child's development, training in particular skills and graded behavioural programmes like those that have been developed for adolescents can be helpful, ${ }^{30}$ as well as family treatment. ${ }^{31}$

\section{Long term management}

Long term success of organ transplantation depends on adherence to medical regimens and treatments over extended periods of time. Noncompliance can be a considerable problem, particularly in young teenage recipients. Fine reported that three quarters of the recipients of renal transplants who admitted to not taking their drugs subsequently lost their graft (R Fine. Non-compliance in paediatric patients with chronic renal failure. Paper presented at 20th annual conference of European working group on the psychosocial aspects of children with chronic renal failure. Hanover, 1989). Much work has been done on this problem, the main variables being (a) the characteristics of the treatment regimen: side effects, duration, and complexity; (b) the doctor-patient relationship: dissatisfaction with consultations, and long waiting time; (c) family factors: instability or discord, poor communication, lack of support from family members, maternal mood, poor maternal understanding of treatment, and lack of supervision. Other variables are individual characteristics: age (adolescence), sex (female), poor understanding, perceived vulnerability and doubts about the effectiveness of the treatment, and psychological problems before treatment.

A number of approaches aimed at increasing compliance have been described. ${ }^{32}$ It is worth approaching the problem step by step, firstly by addressing the patient's understanding and active misconceptions about regimens of treatment. If it is clear that the patient has not understood the requirements, compliance can be improved by: reducing the complexity of the regimen, and providing written supporting material, either in the form of a handout or a booklet that the patient keeps. Should the educational approach be insufficient, the second step is to assess the motivation of the young person or family. With adolescents, where the attainment of autonomy and independence are uppermost, it is sometimes possible to manage the problem by increasing the patient's sense of control by negotiating which drugs they need to take and when, coupled with increased medical supervision. In teenage girls noncompliance is commonly associated with cosmetic side effects such as excessive weight gain, cushingoid features, and hirsutism. When possible the team needs to help the child solve these difficulties within the context of adequate medical treatment-for example, by using an alternative immunosuppressive drug, providing dietary advice, depilatories, and other cosmetic measures when the problem is severe. Finally, psychological or family issues may play an important part, necessitating referral to other specialists.

As transplantation programmes become increasingly successful, the assessment of quality of life is becoming more important. ${ }^{34}$ For example, patients who received liver transplants need fewer admissions to hospital and drugs than they did before operation, their growth and general development have increased. ${ }^{35}$ Other studies have highlighted some children who have persistent delays, and point out that positive outcomes such as catch up growth are usually determined by factors such as age, height, and bone age before the transplant. ${ }^{36}$ 
It is often assumed that children who have received transplants have serious mental health problems but the evidence is inconclusive. Children who have received liver transplants have been described as having appreciable psychological problems, ${ }^{29}$ whereas most children with renal transplants are said to be well adjusted on formal psychiatric and psychological assessments. ${ }^{37} 38$

There is also a suggestion that children have emotional problems in accepting and integrating the new organ. On balance the evidence does not support this, although cases of children experiencing difficulties do occur. They tend, however, to be children who had emotional problems before the transplant, and in these cases the transplant is likely to colour the way in which distress is manifested rather than be a causal factor in itself.

There is firmer evidence that children with transplants feel differently about themselves compared. with most other healthy children, particularly in terms of self esteem and body image. Many authors comment on the children's sensitivity about the physical changes caused by immunosuppressive drugs, their reactions to scars, their persisting short stature, and deformities caused by bone disease. ${ }^{37}$ It is important to identify dissatisfaction with body image early on, as follow up studies suggest that such difficulties are associated with problems of emotional and social adjustment in later life. ${ }^{28} 38$

Parents report difficulties in achieving an appropriate balance between protectiveness and independence at this stage. The main areas of concern are re-establishing old family patterns of interaction, coping with worries about the future, and the side effects of medication. ${ }^{4} \mathrm{~A}$ particular stress is the death of another child, as this can reawaken their own sense of vulnerability. In the case of renal transplantation, failure of the graft necessitating a return to dialysis is a similar factor. Evidence suggests that when good functioning of the graft is established, normal family routines reestablish themselves within a year. ${ }^{39}$ Studies of families in which a child has received a liver transplant suggest that parental problems in adjustment are more entrenched. ${ }^{4} 35$ This is possibly because of the higher incidence of rejection and complications, as well as the lack of alternative treatments if transplantation fails.

The above arguments indicate a need for regular psychosocial reviews to be built into the medical outpatient assessment, so that problems can be identified early and appropriate help provided. There are critical transition points in the life cycles of families that can delay successful adaptation. Consultations need to focus not only on medical aspects, but also more general issues, such as how the family are coping and whether the child's development is appropriate for age, as it is only in integrating psychosocial and medical factors that optimal care can be provided.

RB was supported by a grant from the Children's Liver Disease Foundation.

Mowat A. Liver disorders in childhood. London: Butterworth 1987

2 Smyth RL, Higenbottam TW, Scott JP, et al. Early experience of heart-lung transplantation. Arch Dis Child 1989;64:1225-30.

3 Rigden S, Ward G, Turner C, et al. Twenty years experience of renal transplantation in children. Arch Dis Child 1989; 64:1215.

4 Gold L, Kirkpatrick B, Fricker F, Zitelli B. Psychosocial issues in pediatric organ transplantation: the parents' perspective Pediatrics 1986;77:738-44.

5 Mattson A Long term adjustment to physical illness in childhood: a challenge to psychosocial adjustment. Pediatrics 1972;50:801-11.

6 Boyle CM. Differences between patients' and doctors' interpretations of common medical terms. Br Med $\mathcal{J}$ 1970;ii: $286-9$.

7 Roth H, Caron H, Ort R, et al. Patient's beliefs about peptic ulcer and its' treatment. Ann Intern Med 1962;56:72-80.

8 Bradford R. Parents' experiences of the care provided by medical services whilst looking after a chronically ill child. Early Child Development and Care (in press).

9 Slavin L, O'Malley J, Koocher G, Foster D. Communication of the cancer diagnosis to pediatric patients:impact on longterm adjustment. Am J Psychiatry 1982;139:179-83.

10 Pettle-Michael S, Lansdown R. Adjustment to the death of a sibling. Arch Dis Child 1986;61:278-83.

11 Bibace R, Walsh H. Development of children's concept of illness. Pediatrics 1980;66:912-7.

12 Eiser C. The psychology of childhood illness. New York: Springer Verlag, 1985.

13 Pantell R, Stewart T, Dias J, et al. Physician communication with children and parents. Pediatrics 1982;70:396-402.

14 Bradford R. Short report: the importance of psychosocial factors in understanding child distress during routine $\mathrm{X}$-ray procedures. I Child Psychol Psychiatry (in press)

15 Wallander J, Varni J, Babani L, et al. Family resources as resistance factors for psychological maladjustment in chronically ill and handicapped children. $\mathcal{F}$ Pediatr Psychol 1989;14:157-73.

16 Visintainer M, Wolfer J. Psychological preparation for surgical paediatric patients. The effect on children's and parents' stress responses and adjustments. Pediatrics 1975;52: 187-202.

17 Azarnoff $P$, Woody P. Preparation of children for hospitalisation in acute care hospitals in the United States. Pediatrics 1981;68:361-8.

18 Melamed B, Siegel L. Reduction of anxiety in children facing hospitalisation and surgery by use of filmed modelling. hospitalisation and surgery by use of

19 Cassel S, Paul M. The role of puppet therapy on the emotional responses of children hospitalised for cardiac catheternal responses of children hospitalised

20 Woolley H, Stein A, Forrest G, Baum JD. Staff stress and job satisfaction at a children's hospice. Arch Dis Child 1989;64: satisfactic

21 Raphael B. The anatomy of bereavement: $a$ handbook for the caring professions. London: Unwin Hyman, 1984

22 Miles C, Carter C. Sources of parental stress in pediatric intensive care units. Child Health Care 1982;11:65-9.

23 Kavanagh C. Psychological intervention with the severely burned child: report of an experimental comparison of two approaches and their effect on psychological sequalae. Fournal of the American Academy of Child Psychiatry 1983 $145-56$.

24 Hilgard J, LeBarron S. Hypnotherapy of pain in children with cancer. Los Alto, California: William Kaufman, 1984.

25 Zastowny T, Kirschenbaum D, Meng A. Coping skills training for children: effects on distress before, during and after

26 Jay S, Elliott C, Ozolins M, et al. Behavioural management of children's distress during painful medical procedures. children's distress during painf
Behav Res Ther 1985;23:513-20.

27 Korsch B, Fine R, Grushkin C, Negrete VF. Experiences with children and their families during extended haemodialysis and kidney transplantation. Pediatr Clin North Am 1971;18:625-637.

28 Brookes A. A survey of children treated for 5 years or more by dialysis or transplantation to determine the quality of life in long-term survivors of chronic renal failure. Fournal of Child Psychology and Psychiatry Newsletter 1983;00:7-12.

29 House R, Dubovsky S, Penn I. Psychiatric aspects of hepatic transplantation. Transplantation 1983;36:146-50.

30 Magrab P, Jacobstein D. Adolescents coping with renal disease and haemodialysis. Dialysis and Transplantation 1984; 13:151-5.

31 Lask B, Matthew D. Childhood asthma: a controlled trial of family psychotherapy. Arch Dis Child 1979;54:116-9.

32 Ley P. Communicating with patients: improving communication, satisfaction and compliance. London: Croom Helm, 1988.

33 Coupey S, Cohen $M$. Special considerations for the health care of adolescents with chronic illness. Pediatr Clin North Am 1984;31:211-9.

34 Henning P, Tomlinson L, Rigden S, et al. Long term outcome ot treatment of end-stage renal failure in childhood. Arch Dis Child 1988;63:35-40.

35 Zitelli B, Miller J, Gartner C, et al. Changes in life style after liver transplantation. Pediatrics 1988;82:173-80.

36 Rizzoni G, Broyer M, Guest G, et al. Growth retardation in children with chronic renal disease: scope of the problem. Am $\mathcal{F}$ Kidney Dis 1988;7:256-61.

37 Bernstein DM. Psychiatric assessment of the adjustment of transplanted children. In: Simmons R, Klein S, Simmons $\mathrm{R}$, eds. Gift of life: the social and psychological impact of organ transplantation. Chichester: Wiley, 1977:119-45.

38 Klein S, Simmons R, Anderson C. Chronic kidney disease and transplantation in childhood and adolescence. In: Blum $\mathrm{R}$, ed. Chronic illness and disabilities in childhood and adolescence. New York: Grune and Stratton, 1984:429-57.

39 Korsch B, Negrete V, Garcher J, et al. Kidney transplantation in children: psychosocial follow-up study on child and family. 7 Pediatr 1973;83:399-408. 